\title{
Acute Kidney Injury in Term Babies with Persistent Pulmonary Hypertension of the Newborn
}

\author{
Mohamed M. Sheta ${ }^{1}$, Abeer I. Al-Khalafawi ${ }^{2}$, Syed M. Raza ${ }^{3}$, Suzan S. Gad ${ }^{4} \&$ Mervat A. Hesham ${ }^{5}$ \\ ${ }^{1}$ Department of Pediatrics, Mansoura General Hospital, Mansoura, Egypt \\ ${ }^{2}$ Department of Pediatrics, Ras Elkheima Hospital, Ras Elkheima, UAE \\ ${ }^{3}$ Department of Pediatrics, Sheikh Khalifa Medical City, Ajman, UAE \\ ${ }^{4}$ Department of Pediatrics, Suez Canal University, Ismailia, Egypt \\ ${ }^{5}$ Department of Pediatrics, Zagazig University, Zagazig, Egypt
}

Correspondence: Mohamed M. Sheta, Department of Pediatrics, Mansoura General Hospital, Mansoura, Egypt. Tel: 971-559-865-166. E-mail: sheta99999@yahoo.com

Received: August 18, 2019 Accepted: September 10, 2019 Online Published: September 13, 2019

doi:10.5539/gjhs.v11n11p60 URL: https://doi.org/10.5539/gjhs.v11n11p60

\begin{abstract}
Objective: The study aimed to determine the prevalence of acute kidney injury (AKI) in term neonates with persistent pulmonary hypertension of the newborn (PPHN), to identify the probable risk factors, and to find its relation to mortality.
\end{abstract}

Methods: The study recruited 758 term neonates admitted to the neonatal ICU (NICU). Diagnosis of PPHN was established on the basis of clinical and echocardiographic criteria. For diagnosis of AKI, we adopted the modified Kidney Disease: Improving Global Outcomes (KDIGO) AKI definition. This definition has three grades of AKI severity depending on degree of serum creatinine rise and urinary output. Patients were followed until they died or discharged from NICU.

Results: Among the 758 term neonates included in the study, there were 47 babies $(6.2 \%)$ fulfilling the criteria of PPHN. AKI was reported in 16 patients $(34.0 \%)$ and the reported mortality rate was $31.9 \%$. Neonates with AKI had significantly higher mortality rate when compared with patients without AKI $(75.0 \%$ versus $9.7 \%$; $=$ 0.0001). A significant association was noted between severe grades of PPHN and AKI.

Conclusions: AKI is prevalent in neonates with PPHN. It is significantly associated with mortality. There is suggested link between AKI and severity of PPHN.

Keywords: persistent pulmonary hypertension of the neonate, acute kidney injury, neonatal intensive care unit

\section{Introduction}

Persistent pulmonary hypertension of the newborn (PPHN) is a serious clinical condition associated with significant mortality and detrimental complications (Roofthooft, Elema, Bergman, \& Berger, 2011).

One-year mortality varied from $7.6 \%$ in an American study (Steurer et al., 2017) to 39.5\% in the Thai study of Nakwan and Pithaklimnuwong (2016) and 25.0 \% in the Egyptian study of Abdel Mohsen and Amin (2013). This discrepancy in the mortality rates reflects the multi-dimensional difference between health systems in developed and developing countries which is one of the challenging issues in the management of PPHN.

Acute kidney injury (AKI) is commonly encountered in neonatal intensive care unit (NICU) and is associated with increased mortality and prolonged hospital stay (Ghobrial, Elhouchi, Eltatawy, \& Beshara, 2018; Jetton et al., 2017; Shalaby et al., 2018). However, its value as a predictor of mortality in NICU is shaded by the variable definitions adopted by different studies (Kastl, 2017). While ongoing research is underway to solve this problem (Jetton et al., 2016), the neonatal modified Kidney Disease: Improving Global Outcomes (KDIGO) AKI definition was recommended to unify and compare research outcomes in neonatal AKI (Selewski et al., 2015).

The present study sought to estimate the prevalence of AKI in term neonates with PPHN, to determine risk factors associated with the condition, and to uncover its relation with neonatal mortality and morbidity. 


\section{Patients and Methods}

The present prospective study was conducted at Mansoura General Hospital, Mansoura, Egypt, over 3 years. The study recruited 758 term neonates admitted to the NICU. The study protocol was approved by the local ethical committee in accordance with the Declaration of Helsinki on clinical research involving human subjects. Legal guardians of included neonates gave informed consent to participate in the study. Patients were excluded if they have major congenital anomalies including congenital heart disease, congenital diaphragmatic hernia and known renal anomalies or diseases.

Upon admission, patients included in the study were subjected to careful history taking, thorough clinical examination and complete laboratory and radiological assessment. Laboratory work-up included complete blood count, blood glucose, blood culture, serum electrolytes, and arterial blood gases. Diagnosis of PPHN was established on the basis of clinical and echocardiographic criteria (Tanaka, Hayashi, Kitajima, Sumi, \& Fujimura, 2007). PPHN severity was classified according to preductal to postductal difference in transcutaneous oxygen saturation (SO2) and oxygen index (OI) as described by Roofthooft et al. (2011).

For diagnosis of AKI, we adopted the modified KDIGO AKI definition. This definition has three grades of AKI severity depending on degree of serum creatinine rise and urinary output (Jetton \& Askenazi, 2012, 2014). Patients were followed until they died or discharged from NICU.

Statistical analysis of the collected data was performed using SPSS 22 (IBM, USA). Numerical data were represented as mean \pm standard deviation while categorical data were represented as number and percentage. Comparative analysis was achieved by Student $t$ test for numerical data while Chi-square test or Fisher exact test were used for categorical variables. P value less than 0.05 was considered statistically significant.

\section{Results}

Among the 758 term neonates included in the study, there were 47 babies $(6.2 \%)$ with PPHN. The clinical characteristics of those babies are shown in Table 1. AKI was reported in 16 patients $(34.0 \%)$ of the PPHN subgroup. Table- 2 shows the reported causes and grades of PPHN. Comparison between patients with AKI and patients without regarding the clinical data is shown in table-3. Neonates with AKI had significantly higher mortality rate when compared with patients without $(75.0 \%$ versus $9.7 \%$; $=0.0001)$. Comparison between patients with AKI and patients without regarding the causes and grades of PPHN is shown in table-4. Patients with AKI had a significantly higher frequency of cases with very severe PPHN according to the OI. Table- 5 shows no significant relation between PPHN severity and AKI grades.

Table 1. Clinical characteristics of the studied patients $(n=47)$

\begin{tabular}{lll}
\hline Clinical data & & $\mathbf{n}(\mathbf{\%}) /$ median (range) \\
\hline Sex & Male & $29(61.7)$ \\
& Female & $18(38.3)$ \\
\hline Mode of delivery & Vaginal & $16(34.0)$ \\
\hline Birth weight & CS & $31(66.0)$ \\
& AGA & $33(70.2)$ \\
& LGA & $2(4.3)$ \\
\hline Respiratory distress & SGA & $12(25.5)$ \\
& Mild & $12(25.5)$ \\
\hline Cyanosis & Moderate & $28(59.6)$ \\
Cardiomegaly & Severe & $7(14.9)$ \\
Hepatomegaly & & $37(78.7)$ \\
Hypoglycemia & & $17(36.1)$ \\
Hypocalcemia & & $14(29.8)$ \\
\hline
\end{tabular}




\begin{tabular}{ll}
\hline Ventilator-associated pneumonia & $20(42.6)$ \\
Pneumothorax & $18(38.3)$ \\
Seizure & $5(10.6)$ \\
Sepsis & $27(57.4)$ \\
AKI & $16(34.0)$ \\
- Stage 1 & $6(37.5)$ \\
- Stage 2 & $5(31.25)$ \\
- Stage 3 & $5(31.25)$ \\
5 min Apgar score $<7$ & $13(27.7)$ \\
Hospital stay (days) & $9(5-32)$ \\
Mortality & $15(31.9)$
\end{tabular}

CS: cesarean section, AGA: appropriate for gestational age, LGA: large for gestational age, SGA: small for gestational age, AKI: acute kidney injury.

Table 2. Reported causes and grades of PPHN

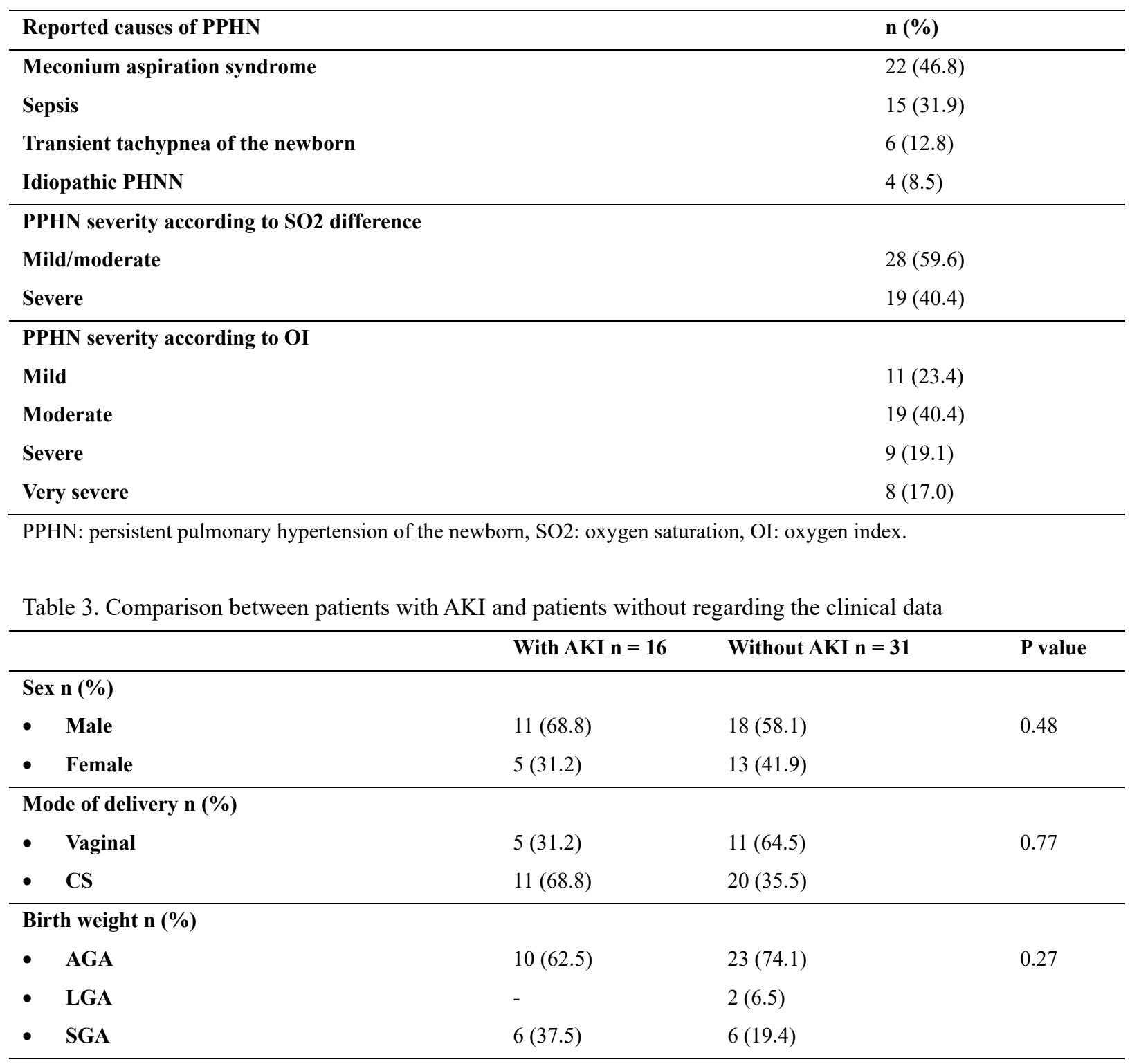




\begin{tabular}{llll}
\hline $\begin{array}{l}\text { Respiratory distress n (\%) } \\
\text { - Mild }\end{array}$ & $4(25.0)$ & $8(25.8)$ & 0.36 \\
- Moderate & $8(50.0)$ & $20(64.5)$ & \\
- Severe & $4(25.0)$ & $3(9.7)$ & 0.76 \\
\hline Cyanosis n (\%) & $13(81.3)$ & $24(77.4)$ & 0.16 \\
Cardiomegaly n (\%) & $8(50.0)$ & $9(29.0)$ & 0.13 \\
Hepatomegaly n (\%) & $7(43.8)$ & $7(22.6)$ & 0.52 \\
Hypoglycemia n (\%) & $5(31.2)$ & $7(22.6)$ & 0.56 \\
Hypocalcemia n (\%) & $6(37.5)$ & $9(29.0)$ & 0.26 \\
Ventilator-associated pneumonia n (\%) & $5(31.2)$ & $15(48.4)$ & 0.07 \\
Pneumothorax n (\%) & $9(56.3)$ & $9(29.0)$ & 0.25 \\
Seizure n (\%) & $3(18.8)$ & $2(6.5)$ & 0.62 \\
Sepsis n (\%) & $10(62.5)$ & $17(54.8)$ & 0.002 \\
5 min Apgar score < 7 n (\%) & $9(56.3)$ & $4(12.9)$ & 0.1 \\
Hospital stay (days) median (range) & $12(5-31)$ & $26(5-32)$ & 0.0001 \\
Mortality n (\%) & $12(75.0)$ & $3(9.7)$ & \\
\hline
\end{tabular}

CS: cesarean section, AGA: appropriate for gestational age, LGA: large for gestational age, SGA: small for gestational age, AKI: acute kidney injury.

Table 4. Comparison between patients with AKI and patients without regarding the causes and grades of PPHN

\begin{tabular}{llll}
\hline & With AKI $\mathbf{n}=\mathbf{1 6}$ & Without AKI $\mathbf{n}=\mathbf{3 1}$ & P value \\
\hline $\begin{array}{l}\text { Reported causes of PPHN } \mathbf{n} \% \\
\text { - Meconium aspiration syndrome }\end{array}$ & $10(62.5)$ & $12(38.7)$ & 0.64 \\
- Sepsis & $4(25.0)$ & $11(35.5)$ & \\
- Transient tachypnea of the newborn & $1(6.25)$ & $5(16.1)$ & \\
- Idiopathic PHNN & $1(6.25)$ & $3(9.7)$ & 0.11 \\
\hline PPHN severity according to SO2 difference $\mathbf{n} \%$ & & & \\
- Mild/moderate & $7(43.8)$ & $21(67.7)$ & 0.028 \\
- Severe & $9(56.2)$ & $10(32.3)$ & \\
\hline PPHN severity according OI $\mathbf{n} \%$ & & & \\
- Mild & $2(12.5)$ & $9(29.0)$ & \\
- Moderate & $4(25.0)$ & $15(48.4)$ & \\
- Severe & $4(25.0)$ & $5(16.1)$ & \\
- Very severe & $6(37.5)$ & $2(6.5)$ & \\
\hline
\end{tabular}

AKI: Acute kidney injury, PPHN: persistent pulmonary hypertension of the newborn, SO2: oxygen saturation, OI: oxygen index. 
Table 5. Relation between PPHN severity and AKI stage in patients with AKI

\begin{tabular}{|c|c|c|c|c|}
\hline & \multicolumn{3}{|c|}{ AKI } & \multirow{2}{*}{ P value } \\
\hline & Stage $1 \mathrm{n}=6$ & Stage $2 n=5$ & Stage $3 n=5$ & \\
\hline \multicolumn{5}{|c|}{ PPHN severity according to SO2 difference n (\%) } \\
\hline - Mild/moderate & $4(66.7)$ & $1(20.0)$ & $2(40.0)$ & \multirow{2}{*}{0.29} \\
\hline - $\quad$ Severe & $2(33.3)$ & $4(80.0)$ & $3(60.0)$ & \\
\hline \multicolumn{5}{|c|}{ PPHN severity according to OI $\mathrm{n}(\%)$} \\
\hline - $\quad$ Mild & $2(33.3)$ & - & - & \multirow{4}{*}{0.46} \\
\hline - Moderate & $2(33.3)$ & $1(20.0)$ & $1(20.0)$ & \\
\hline - $\quad$ Severe & $1(16.65)$ & $2(40.0)$ & $1(20.0)$ & \\
\hline - Very severe & $1(16.65)$ & $2(40.0)$ & $3(60.0)$ & \\
\hline
\end{tabular}

AKI: Acute kidney injury, PPHN: persistent pulmonary hypertension of the newborn, SO2: oxygen saturation, OI: oxygen index.

\section{Discussion}

The prevalence of PPHN in the present study was $6.2 \%$ which is fairly similar to the $5.0 \%$ prevalence reported by Egyptian study of Abdel Mohsen and Amin (2013). There is a scarcity of studies that investigated the link between AKI associated with PPHN and neonatal outcome in the NICU. The present study identified AKI in $34.0 \%$ of patients with PPHN. In comparison, in the study of Kamolvisit, Jaroensri, Ratchatapantanakorn, and Nakwan (2018), AKI was reported in $28.4 \%$ of neonates with PPHN. While both studies adopted the KDIGO classification of AKI, participation in our study was limited to term babies to minimize the problems associated with AKI definition and classification in preterm infants. In the present study, the most commonly reported causes of PPHN were meconium aspiration syndrome (MAS) followed by sepsis and transient tachypnea of the newborn. MAS was the most associated condition with PPHN in the studies of Alano, Ngougmna, Ostrea, and Konduri (2001), Hsieh, Yang, and Fu (2001) and Chotigeat, Champrasert, Khorana, Sangtaweesin, and Kanjanapattanakul (2014).

Patients with AKI in our study experienced significantly lower 5-min. Apgar score and suffered higher mortality rate $(75.0 \%)$. Probably, this may be related to the combined hazards of higher rates of advanced grades of PPHN and AKI noted by the present study. In fact, the association between AKI and NICU mortality was reported by many studies including heterogenous neonatal populations (Kriplani, Sethna, Leisman, \& Schneider, 2016; Miklaszewska et al., 2014; Stojanovic, Barisic, Milanovic, \& Doronjski, 2014; Timovska, Cekovska, \& Tosheska-Trajkovska, 2015).

Of note, the present study revealed a significant association between AKI and PPHN severity as assessed by OI. This novel finding may provide a clinical evidence of some shared pathophysiological mechanisms between PPHN and AKI. Among these, the role of activity of hypoxia induced factors (HIF) was reported in neonates with PPHN (Wedgwood, Lakshminrusimha, Schumacker, \& Steinhorn, 2015). In spite of the fact that the role of HIF in the pathogenesis of neonatal AKI wasn't addressed yet, its role was discussed in experimental studies (An et al., 2013; Ortega et al., 2013). Also, the role of reactive oxygen species was highlighted in PPHN (Afolayan et al., 2012; Wedgwood et al., 2011) and AKI (Plotnikov et al., 2017). However, the exact interaction among various pathophysiological mechanisms underlying both conditions remains to be elucidated.

\section{Conclusions}

AKI is prevalent in neonates with PPHN. It is significantly associated with mortality. There is suggested link between AKI and severity of PPHN.

\section{Competing Interests Statement}

The authors declare that there are no competing or potential conflicts of interest.

\section{References}

Abdel Mohsen, A. H., \& Amin, A. S. (2013). Risk factors and outcomes of persistent pulmonary hypertension of the newborn in neonatal intensive care unit of Al-minya university hospital in egypt. J Clin Neonatol, 2(2), 78-82. https://doi.org/10.4103/2249-4847.116406 
Afolayan, A. J., Eis, A., Teng, R. J., Bakhutashvili, I., Kaul, S., Davis, J. M., \& Konduri, G. G. (2012). Decreases in manganese superoxide dismutase expression and activity contribute to oxidative stress in persistent pulmonary hypertension of the newborn. Am J Physiol Lung Cell Mol Physiol, 303(10), L870-879. https://doi.org/10.1152/ajplung.00098.2012

Alano, M. A., Ngougmna, E., Ostrea, E. M., Jr., \& Konduri, G. G. (2001). Analysis of nonsteroidal antiinflammatory drugs in meconium and its relation to persistent pulmonary hypertension of the newborn. Pediatrics, 107(3), 519-523. https://doi.org/10.1542/peds.107.3.519

An, Y., Zhang, J. Z., Han, J., Yang, H. P., Tie, L., Yang, X. Y., . . Li, X. J. (2013). Hypoxia-inducible factor-1alpha dependent pathways mediate the renoprotective role of acetazolamide against renal ischemia-reperfusion injury. Cell Physiol Biochem, 32(5), 1151-1166. https://doi.org/10.1159/000354515

Chotigeat, U., Champrasert, M., Khorana, M., Sangtaweesin, V., \& Kanjanapattanakul, W. (2014). Iloprost inhalation for the treatment of severe persistent pulmonary hypertension of the newborn, experience at QSNICH. J Med Assoc Thai, 97(Suppl 6), S89-94.

Ghobrial, E. E., Elhouchi, S. Z., Eltatawy, S. S., \& Beshara, L. O. (2018). Risk factors associated with acute kidney injury in newborns. Saudi J Kidney Dis Transpl, 29(1), 81-87. https://doi.org/10.4103/1319-2442.225179

Hsieh, W. S., Yang, P. H., \& Fu, R. H. (2001). Persistent pulmonary hypertension of the newborn: experience in a single institution. Acta Paediatr Taiwan, 42(2), 94-100.

Jetton, J. G., \& Askenazi, D. J. (2012). Update on acute kidney injury in the neonate. Curr Opin Pediatr, 24(2), 191-196. https://doi.org/10.1097/MOP.0b013e32834f62d5

Jetton, J. G., \& Askenazi, D. J. (2014). Acute kidney injury in the neonate. Clin Perinatol, 41(3), 487-502. https://doi.org/10.1016/j.clp.2014.05.001

Jetton, J. G., Boohaker, L. J., Sethi, S. K., Wazir, S., Rohatgi, S., Soranno, D. E., . . Neonatal Kidney, C. (2017). Incidence and outcomes of neonatal acute kidney injury (AWAKEN): a multicentre, multinational, observational cohort study. Lancet Child Adolesc Health, 1(3), 184-194. https://doi.org/10.1016/S2352-4642(17)30069-X

Jetton, J. G., Guillet, R., Askenazi, D. J., Dill, L., Jacobs, J., Kent, A. L., . . Neonatal Kidney, C. (2016). Assessment of Worldwide Acute Kidney Injury Epidemiology in Neonates: Design of a Retrospective Cohort Study. Front Pediatr, 4, 68. https://doi.org/10.3389/fped.2016.00068

Kamolvisit, W., Jaroensri, S., Ratchatapantanakorn, B., \& Nakwan, N. (2018). Factors and Outcomes of Persistent Pulmonary Hypertension of the Newborn Associated with Acute Kidney Injury in Thai Neonates. Am J Perinatol, 35(3), 298-304. https://doi.org/10.1055/s-0037-1607213

Kastl, J. T. (2017). Renal function in the fetus and neonate - the creatinine enigma. Semin Fetal Neonatal Med, 22(2), 83-89. https://doi.org/10.1016/j.siny.2016.12.002

Kriplani, D. S., Sethna, C. B., Leisman, D. E., \& Schneider, J. B. (2016). Acute Kidney Injury in Neonates in the PICU. Pediatr Crit Care Med, 17(4), e159-164. https://doi.org/10.1097/PCC.0000000000000668

Miklaszewska, M., Korohoda, P., Sobczak, A., Horbaczewska, A., Filipiak, A., Zachwieja, K., . . Pietrzyk, J. A. (2014). Acute kidney injury in a single pediatric intensive care unit in Poland: a retrospective study. Kidney Blood Press Res, 39(1), 28-39. https://doi.org/10.1159/000355774

Nakwan, N., \& Pithaklimnuwong, S. (2016). Acute kidney injury and pneumothorax are risk factors for mortality in persistent pulmonary hypertension of the newborn in Thai neonates. J Matern Fetal Neonatal Med, 29(11), 1741-1746. https://doi.org/10.3109/14767058.2015.1060213

Ortega, A., Fernandez, A., Arenas, M. I., Lopez-Luna, P., Munoz-Moreno, C., Arribas, I., . . Bosch, R. J. (2013). Outcome of acute renal injury in diabetic mice with experimental endotoxemia: role of hypoxia-inducible factor-1 alpha. J Diabetes Res, 2013, 254529. https://doi.org/10.1155/2013/254529

Plotnikov, E. Y., Pavlenko, T. A., Pevzner, I. B., Zorova, L. D., Manskikh, V. N., Silachev, D. N., . . Zorov, D. B. (2017). The role of oxidative stress in acute renal injury of newborn rats exposed to hypoxia and endotoxin. FEBS J, 284(18), 3069-3078. https://doi.org/10.1111/febs.14177

Roofthooft, M. T., Elema, A., Bergman, K. A., \& Berger, R. M. (2011). Patient characteristics in persistent pulmonary hypertension of the newborn. Pulm Med, 2011, 858154. https://doi.org/10.1155/2011/858154

Selewski, D. T., Charlton, J. R., Jetton, J. G., Guillet, R., Mhanna, M. J., Askenazi, D. J., \& Kent, A. L. (2015). 
Neonatal Acute Kidney Injury. Pediatrics, 136(2), e463-473. https://doi.org/10.1542/peds.2014-3819

Shalaby, M. A., Sawan, Z. A., Nawawi, E., Alsaedi, S., Al-Wassia, H., \& Kari, J. A. (2018). Incidence, risk factors, and outcome of neonatal acute kidney injury: a prospective cohort study. Pediatr Nephrol, 33(9), 1617-1624. https://doi.org/10.1007/s00467-018-3966-7

Steurer, M. A., Jelliffe-Pawlowski, L. L., Baer, R. J., Partridge, J. C., Rogers, E. E., \& Keller, R. L. (2017). Persistent Pulmonary Hypertension of the Newborn in Late Preterm and Term Infants in California. Pediatrics, 139(1). https://doi.org/10.1542/peds.2016-1165

Stojanovic, V., Barisic, N., Milanovic, B., \& Doronjski, A. (2014). Acute kidney injury in preterm infants admitted to a neonatal intensive care unit. Pediatr Nephrol, 29(11), 2213-2220. https://doi.org/10.1007/s00467-014-2837-0

Tanaka, Y., Hayashi, T., Kitajima, H., Sumi, K., \& Fujimura, M. (2007). Inhaled nitric oxide therapy decreases the risk of cerebral palsy in preterm infants with persistent pulmonary hypertension of the newborn. Pediatrics, 119(6), 1159-1164. https://doi.org/10.1542/peds.2006-2269

Timovska, S. N., Cekovska, S., \& Tosheska-Trajkovska, K. (2015). Acute Kidney Injury in Newborns. Pril (Makedon Akad Nauk Umet Odd Med Nauki), 36(3), 83-89. https://doi.org/10.1515/prilozi-2015-0082

Wedgwood, S., Lakshminrusimha, S., Fukai, T., Russell, J. A., Schumacker, P. T., \& Steinhorn, R. H. (2011). Hydrogen peroxide regulates extracellular superoxide dismutase activity and expression in neonatal pulmonary hypertension. Antioxid Redox Signal, 15(6), 1497-1506. https://doi.org/10.1089/ars.2010.3630

Wedgwood, S., Lakshminrusimha, S., Schumacker, P. T., \& Steinhorn, R. H. (2015). Hypoxia inducible factor signaling and experimental persistent pulmonary hypertension of the newborn. Front Pharmacol, 6, 47. https://doi.org/10.3389/fphar.2015.00047

\section{Copyrights}

Copyright for this article is retained by the author(s), with first publication rights granted to the journal.

This is an open-access article distributed under the terms and conditions of the Creative Commons Attribution license (http://creativecommons.org/licenses/by/4.0/). 